\title{
Quebec reforms: necessary or overkill?
}

$\mathrm{T}$

he health care system in Quebec is undergoing an overhaul. Two sweeping pieces of legislation, Bill 10 and Bill 20, have created so much controversy that the process is being called a bulldozer reform by physicians who fear it will upset their practices and affect their ability to provide quality care.

Physicians say the proposed changes will also be cumbersome and force them to give up research and teaching in order to meet patient quotas. A mathematical question will enter doctors' minds when considering taking on a research project, says Dr. Maxine Dumas-Pilon, president of the Collège québécois des médecins de famille. That question is: "How many patients does that count for?" she says.

Bill 20 (CMAJ 2015;187:20) is now going through Quebec's National Assembly, although a majority government in power practically assures passage. To increase access to family doctors, the bill will require family doctors to work at least 12 hours a week in the public system and take on as many as 1512 patients or face a penalty of up to $30 \%$ of their income.

The number of patients assigned to a family doctor will depend on seniority and years of practice. According to preliminary tables, a family doctor with 5-14 years of practice, for example, will have to take on 1008 patients. But that number falls to 828 if that doctor teaches six hours a week in a medical school for 30 weeks a year. Family doctors with 25-34 years of experience will be expected to take on 1512 patients but are not required to put in 12 hours a week in hospitals. Consultants will have to be more available and respond to $75 \%$ of referrals in hospital emergency units within a four-hour period or face financial penalties.

Recently, Minister of Health and Social Services Dr. Gaétan Barrette pushed through Bill 10, which amal-
2017 — by increasing access because every patient is different and their needs vary.

His blunt analysis has raised eyebrows. Antonia Maioni, a professor at the Institute for Health and Social Policy at McGill University in Montréal, says the reform is well-intentioned but that this huge endeavour "is trying to import or graft on to the system principles and policies that work in other contexts that will not necessarily translate well in a fee-for-service system in primary care."

The real concern for physicians, says Maoini, is that they work in a system where they're supposed to be autonomous. They are not employees of the state, but organizational changes may open the door to more of an encroachment on physician autonomy from the ministry of health and the minister himself.

"The issue of autonomy is really the line in the sand for doctors right across Canada."

Dumas-Pilon agrees. Barrette's message to family doctors is that if they're not able to organize themselves, "we'll tell them what to do."

She says the two bills were pushed through without any consultation and without looking at initiatives that were already underway. Bill 20 will undo some of the recent efforts to raise the profile of family doctors, she says, but the main concern is that it addresses only access to health care, focussing on the productivity of doctors instead of the total care of the patient.

It's not true that everything has been tried and doesn't work, she says, suggesting that financial incentives for doctors over the past decade have improved care for patients who are older or have chronic conditions. - Huguette Young, Ottawa, Ont.

CMAJ 2015. DOI:10.1503/cmaj.109-5052 